Military Technical College Kobry El-Kobbah, Cairo, Egypt

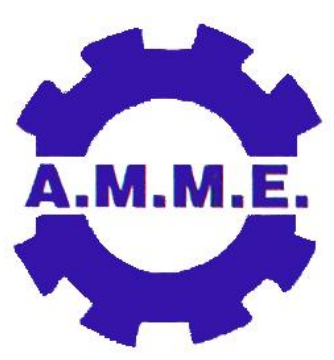

$14^{\text {th }}$ International Conference on Applied Mechanics and Mechanical Engineering.

\title{
NUMERICAL INVESTIGATION OF PROEJECTILE PENETRATION INTO CERAMIC/STEEL TARGETS
}

By

H.A. Abou-Elela*, A.M. Riad* and A.I. Fayed ${ }^{*}$

\begin{abstract}
In this paper, Autodyn-2D hydrocode is used to simulate the penetration process of a small caliber projectile into a ceramic tile with finite thickness backed by a semi-infinite 4340 steel armor. Input data to the code are those used by Reaugh, et al. [1]. These data include six types of ceramic material, projectile material and 4340 semi-infinte steel armor, respectively. The ceramic material types are: Alumina with purity 85 and $96 \%$, respectively, Boron Carbide, Aluminium Nitride, Silicon Carbide and Titanium Diboride. Each tile thickness of a ceramic material type is backed by a 4340 steel semi-infinite armor to form a bi-element target; each target is impacted by a tungesten alloy projectile having a certain velocity in the range from 1300 to $1750 \mathrm{~m} / \mathrm{s}$. The main procedures used to simulate the penetration process are introduced.
\end{abstract}

The obtained numerial results of Autodyn-2D are compared with the corresponding experimental measurments of Ref. [1]; good agreement is generally obtained. In addition, samples of the time histories predicted by the hydrocode are presented, together with pertinent analyses and discussions. Finally, It is concluded that the Autodyn-2D hydrocode is a useful tool in designing and evaluating the ballistic efficiency of a bielement target when encountering a certain threat.

KEY WORDS: Bi-element targets, ceramics, penetration, erosion, ceramic/metal targets, semi- infinite targets, Autodyn, numerical simulation. 


\section{* Egyptian Armed Forces. INTRODUCTION}

Numerical simulation is one of the main approaches used to study the ballistic impact and penetration phenomena, and helps in armor design since high capacity and high speed computers are available. It also has a low-cost compared to that of actual experiments. It decreases the number of needed experiments, especially in case of a bi-element target where many materials with different configurations are available as candidates in armor design optimization. Moreover, numerical simulation efficiency reveals when studying impact phenomena in a wide range of impact velocities and high obliquity, where experimental work will be very costly.

Rosenberg, et al. [2] simulated the experimental tests performed by Hohler, et al. [3] using Pisces 2-D code. They fed the code with the experimental data of Ref. [3] for tungsten alloy rods having $\mathrm{L} / \mathrm{D}=10$ and diameters of $12.5 \mathrm{~mm}$, bi-element targets consisting of AD85 alumina with different thicknesses facing semi-infinite steel armor, and impact velocities ranging from 1.25 to $3 \mathrm{~km} / \mathrm{s}$, respectively. The behavior of alumina was represented by Johnson-Holmquist model and its intact strength was calculated as function of Hogonoit Elastic Limit [HEL].

The numerical results of Rosenberg, et al. gave good agreement with the measured penetration depths of Ref. [3]. Rosenberg, et al. extended their simulation work to study the effect of ceramic tile thickness and its lateral dimensions on its performance. They predicted that the tile diameter must be at least five times larger than its thickness, depending on impact velocity. For alumina ceramic type, the ratio of residual penetration into the backing armor to ceramic tile thickness was constant and this ratio was independent of either tile thickness or impact velocity over the range of velocity and thickness investigated.

Holmquist, et al. [4] studied numerically the penetration process of a tungeten alloy projectile into a bi-element target, consisiting of an Aluminim Nitride (AIN) ceramic tile with finite thickness backed by a semi-infinite steel armor, using Autodyn-2D hydrocode. They introduced the constitutive modelling of AIN ceramic material under impact condition using Johnson Holmquist model ( $\mathrm{JH}-2)$. The constants for AIN ceramic type were determined explicitly by matching the measurements of Reaugh, et al. [1] and the corresponding computations at high-velocity penetration. All other materials were modeled in Autodyn-2D hydrocode using Johnson-Cook strength and fracture models, and Mie-Gruneisen equation of state.

Numerical results of Ref. [4] gave good agreement with the corresponding measured penetration depths of Ref. [1]; the maximum error was found to be $20 \%$ at the impact velocity of $1250 \mathrm{~m} / \mathrm{s}$. They also simulated the impct of tungsten projectile, having a diameter of $8.33 \mathrm{~mm}$ and an aspect ratio of 6 , into layered AIN ceramic tile facing a semiinfinite aluminum armor at $V_{i}=1120 \mathrm{~m} / \mathrm{s}$. Layered tiles consisted of 1, 2, 3, and 6 layers, respectively; each layer had a thickness of $19.05 \mathrm{~mm}$. Their numerical simulation results gave good agreement with the corresponding experimental measurements of Ref. [5]; the maximum error was $10 \%$.

Holmquist and Johnson [6] studied numerically the responses of thin and thick ceramic targets, with and without prestress, due to projectile impact. For both targets, two 
prestress levels (small and large), and two prestress states (radial and hydrostatic) were investigated. The small prestress was similar in magnitude to a value obtained experimentally, whereas the large prestress was approximately the maximum prestress that could be produced due to confinement. The targets were subjected to projectile impact and their ballistic responses were evaluated. For thin targets consisting of AD99.5 alumina ceramic tile surrounded by titanium confinement, and of silicon carbide ceramic tile confined into steel sleeve, the prestress increased the projectile/ceramic interaction time which, consequently, improved their ballistic performance. For thick targets, the magnitude of the prestress obtained was greater than that of thin targets because the top and bottom plates were thicker and provided more confinement. The order of thick targets according to their performance (high to low) was: (i) targets with hydrostatic prestress, (ii) targets with radial prestress and (iii) targets without prestress. The difference in performance increased with the increase of impact velocity and value of prestressing.

Quan, et al. [7] simulated the penetration of tungsten/ molybdenum long rods into silicon carbide ( $\mathrm{SiC})$ ceramic tiles with two different configurations at different impact velocities using Autodyn-3D. Ceramic material in both cases was modeled using JohnsonHolmquist constitutive model $(\mathrm{JH}-1)$. Their input data to the hydrocode were those used in the two experimental programs of other investigators. The first program was done by Westerling, et al. [8] who tested the impact of SiC ceramic targets confined in steel cylinder by projectiles made of tungsten/ molybdenum at velocities ranging from 1400 to $2500 \mathrm{~m} / \mathrm{s}$. The second was selected from the experimental program of Reaugh, et al. [1] who tested each $\mathrm{SiC}$ ceramic tile thickness facing a semi-infinite-steel armor by tungsten alloy projectile at impact velocities in the range from 1370 to $1800 \mathrm{~m} / \mathrm{s}$.

Quan, et al. [7] used two values of ceramic damage constant to simulate the series of tests performed by Westerling, et al. [8]. These constant values were determined by matching the predicted penetration depth obtained by Autodyn-3D with the corresponding experimental measurement of Ref. [8]. In addition, the results of the Autodyn-3D were also compared with the corresponding measurements of Ref. [1]; good agreement was obtained. The maximum error was found to be $28.2 \%$ at normal impact. Despite these errors, the authors argued that the $\mathrm{JH}-1$ model, as implemented in Autodyn-3D, represents a powerful numerical tool for designing and analysing ceramic armor systems.

In this paper, Autodyn-2D is used to simulate the normal and oblique impact of a cylindrical projectile, into a bi-element target, consisting of a ceramic tile facing a semiinfinite metallic armor, at different velocities. The numerical simulations were established according to the tested bi-element targets in the experimental program of Ref. [1], where six types of ceramic tiles with different thicknesses were used. The obtained numerical results are compared with the corresponding experimental measurements of Ref. [1]. In addition, samples of the obtained numerical results will be presented and pertinent analyses and discussions will be made.

\section{NUMERICAL SIMULATION}

Autodyn-2D is an explicit integration code where the physical equations of mass, momentum and energy conservation coupled with material descriptions are solved. Alternative numerical processors are available and can be selectively used to model different regions of a problem [9]. In Autodyn-2D hydrocode, the complex problem is required to be broken up into finite number of smaller and simpler problems. This process 
is called discretization, where the equations need to be discretized in (time, space). Also, the code includes an erosion algorithm which enhances the ability of the Lagrange processor to simulate impact problems where large deformations occur. It also allows automatic deletion of cells during the subsequent calculation when their strain value reaches the erosion strain value [10].

Autodyn-2D is used herein to simulate the normal and oblique impact of a cylindrical projectile, made of tungsten alloy and having a diameter of $6.35 \mathrm{~mm}$ and an aspect ratio of 4 , into a bi-element target, consisting of a square ceramic tile facing a square semiinfinite 4340 steel armor, at different velocities; Cf. Fig.1. The numerical simulations were run using the data of tested bi-element targets in the experimental program of Ref. [1].

\section{Model Representation Procedures in Autodyn-2D Hydrocode}

To model any system, it must be drawn considering its datum point or zero origin. Each material or component is discretized into forming cells or meshes. Each mesh interacts with another one by defined strength model for each material that has an Equation Of State (EOS). The main representation procedures of any impact problem in Autodyn-2D are listed in Ref. [10]. In case of oblique impact, the input ceramic thickness to Autodyn code, $\mathrm{H}_{\mathrm{co}}$ simu, represents the path of projectile into ceramic tile [i.e. $\mathrm{H}_{\mathrm{co}}$ simu = $\mathrm{H}_{\mathrm{co}} / \operatorname{Cos}\left(\boldsymbol{\theta}^{\circ}\right)$ ], where " $\boldsymbol{\theta}^{\circ}$ " is the impact angle measured from the normal to the surface of ceramic tile. Both normal and oblique impacts have been taken as axisymmetry to decrease the solving time.

Material Data

\section{Data of projectile material}

The material used for filling the meshes of projectile grids was tungsten alloy. The selected strength model for the projectile material was "Von-Mises", where its erosion model was selected to be "incremental geometric strain". Moreover, The equation of state for the projectile material was "linear" and its failure model was "plastic strain". The input data of the projectile to the hydrocode are listed in Table $1[1,7]$.

\section{Data of ceramic materials}

Six types of ceramic materials were used in the present work. The behavior of each ceramic material has been modeled using "linear" equation of state, "Johnson-Holmquist" (JH-2) model for its strength and failure, respectively, and "incremental geometrical strain" model for its erosion. The input data of the six types of ceramic materials are listed in Table 2 [1].

\section{Material data for semi-infinite $\mathbf{4 3 4 0}$ steel armor}

The material used for filling the meshes of semi-infinte backing armor grids was 4340 steel. The behahavior of semi-infinite steel target has been modeled using "linear" equation of state, "Johnson Cook" model for its strength and failure, respectively, and "incremental geometrical strain" model for its erosion. The input data of the semi-infinite armor material to the hydrocode are listed in Table $3[1,7]$. 


\section{Material Models}

In general, materials have a complex response to dynamic loading. In the following, the different models used to represent the projectile, ceramic types and semi-infinite metallic armor materials, respectively, are presented.

\section{Equation of state}

In the present simulation, a "linear" equation of state is used to represent the equation of state for projectile, ceramic tile, and semi-infinite armor materials, respectively. This equation is expressed by [11]:

$$
P(\rho)=K . \mu
$$

where

$$
\mu=\left(\left(\rho / \rho_{\circ}\right)-1\right),
$$

$\mathrm{P}$ is the pressure, $\mathrm{K}$ is the bulk modulus of the respective material, $\mu$ is the compression ratio, $\rho$ is the density of compressed material, and $\rho_{0}$ is its initial density.

\section{Strength model}

Solid materials may initially respond elastically, but under extreme shock loadings, they reach stress states that exceed their yield stress and deform plastically. Material strength equation that describes the non-linear elasto-plastic response for the projectile material is selected to follow "Von-Mises" equation [11]. This equation determines the elastic limit and the transition

Table 1. Input data to Autodyn-2D hydrocode for the tungsten projectile $[1,7]$.

\begin{tabular}{|l|c|l|c|}
\hline \multicolumn{1}{|c|}{ Parameter } & Value & \multicolumn{1}{c|}{ Parameter } & Value \\
\hline Penetrator length, $(\mathrm{mm})$ & 25.4 & $\begin{array}{l}\text { Reference temperature, } \\
(\mathrm{K})\end{array}$ & 293 \\
\hline $\begin{array}{l}\text { Penetrator diameter, }(\mathrm{mm}) \\
\begin{array}{l}\text { Reference density, } \\
\left(\mathrm{g} / \mathrm{cm}^{3}\right)\end{array}\end{array}$ & 6.35 & Shear Modulus, $(\mathrm{kPa})$ & $1.6 \mathrm{E}+8$ \\
\hline Bulk Modulus, $(\mathrm{kPa})$ & $2.85 \mathrm{E}+8$ & Yield Stress, $(\mathrm{kPa})$ & $1.2 \mathrm{E}+6$ \\
\hline
\end{tabular}


Table 2. Input data to Autodyn-2D code for different ceramic materials [1].

\begin{tabular}{|c|c|c|c|c|c|c|}
\hline Parameter & AD85 & AD96 & $\mathrm{B}_{4} \mathrm{C}$ & SiC & AIN & $\mathrm{TiB}_{2}$ \\
\hline Thickness, (mm) & \multicolumn{6}{|c|}{ variable } \\
\hline Reference density, $\left(\mathrm{g} / \mathrm{cm}^{3}\right)$ & 3.4 & 3.75 & 2.51 & 3.31 & 3.25 & 4.49 \\
\hline Bulk Modulus, (kPa) & $1.53 \mathrm{E}+8$ & $\begin{array}{c}1.913 \mathrm{E}+ \\
8\end{array}$ & $\begin{array}{l}2.52 \mathrm{E}+ \\
8\end{array}$ & $\begin{array}{l}1.98 \mathrm{E}+ \\
8\end{array}$ & $\begin{array}{l}2.01 \mathrm{E}+ \\
8\end{array}$ & $\begin{array}{l}1.68 \mathrm{E}+ \\
8\end{array}$ \\
\hline Reference temperature, (K) & \multicolumn{6}{|c|}{293} \\
\hline Shear Modulus, (kPa) & $8.9 \mathrm{E}+7$ & $\begin{array}{l}1.52 \mathrm{E}+ \\
8\end{array}$ & $\begin{array}{c}1.99 E+ \\
8\end{array}$ & $\begin{array}{c}1.74 \mathrm{E}+ \\
8\end{array}$ & $\begin{array}{l}1.27 \mathrm{E}+ \\
8\end{array}$ & $1.9 \mathrm{E}+8$ \\
\hline Hugoniot elastic limit, (kPa) & $6 \mathrm{E}+6$ & $6.5 \mathrm{E}+6$ & $7 \mathrm{E}+6$ & $7.7 \mathrm{E}+6$ & $8 \mathrm{E}+6$ & $\begin{array}{c}11.8 \mathrm{E}+ \\
6\end{array}$ \\
\hline Intact strength constant, A & 0.88 & 0.88 & 0.927 & 0.96 & 0.85 & 0.989 \\
\hline Intact strength exponent, $\mathrm{N}$ & 0.64 & 0.64 & 0.67 & 0.65 & 0.29 & 0.3755 \\
\hline Strain rate constant, $\mathrm{C}$ & 0.00 & 0.007 & 0.005 & 0.0 & 0.013 & 0.0 \\
\hline $\begin{array}{l}\text { Fractured strength constant, } \\
\text { B }\end{array}$ & 0.28 & 0.28 & 0.9 & 0.17 & 0.31 & 0.77 \\
\hline $\begin{array}{l}\text { Fractured strength exponent, } \\
M\end{array}$ & 0.6 & 0.6 & 0.85 & 0.8 & 0.21 & 1 \\
\hline Max. fracture strength ratio & 0.5 & 1 & 0.2 & 0.8 & 1 & 0.5 \\
\hline Hydro tensile limit (kPa) & $-2 E+5$ & $-2.6 E+5$ & $2.6 \bar{E}+5$ & $3.7 \bar{E}+5$ & $3.2 \bar{E}+5$ & $6.8 \bar{E}+5$ \\
\hline Damage constant, $\mathrm{D}_{1}$ & 0.01 & 0.01 & 0.01 & 0.48 & 0.02 & 0.01 \\
\hline Damage constant, $\mathrm{D}_{2}$ & 0.7 & 0.7 & 0.5 & 0.48 & 1.85 & 1 \\
\hline Bulking constant, Beta & 1 & 1 & 1 & 1 & 1 & 1 \\
\hline Damage type & \multicolumn{6}{|c|}{$\mathrm{JH}-2$} \\
\hline Tensile failure & \multicolumn{6}{|c|}{ Hydro } \\
\hline Erosion strain & 2 & 1.5 & 1.9 & 1 & 1.4 & 2 \\
\hline
\end{tabular}

Table 3. Input data to Autodyn-2D code for the semi-infinite 4340 steel $[1,7]$.

\begin{tabular}{|l|c|l|c|}
\hline \multicolumn{1}{|c|}{ Parameter } & Value & \multicolumn{1}{c|}{ Parameter } & Value \\
\hline Reference density $\left(\mathrm{g} / \mathrm{cm}^{3}\right)$ & 7.85 & Ref. Strain rate, $\left(\mathrm{s}^{-1}\right)$ & 1 \\
\hline Bulk Modulus $(\mathrm{kPa})$ & $1.59 \mathrm{E}+8$ & Strain rate correction & $1^{\text {st }}$ order \\
\hline Reference temperature $(\mathrm{K})$ & 300 & Damage constant, $\mathrm{D}_{1}$ & 0.05 \\
\hline Shear Modulus $(\mathrm{kPa})$ & $7.7 \mathrm{E}+7$ & Damage constant, $\mathrm{D}_{2}$ & 3.44 \\
\hline Yield Stress A $(\mathrm{kPa})$ & $7.92 \mathrm{E}+5$ & Damage constant, $\mathrm{D}_{3}$ & -2.12 \\
\hline Hardening constant, $\mathrm{B}$ & $5.1 \mathrm{E}+5$ & Damage constant, $\mathrm{D}_{4}$ & 0.003 \\
\hline Hardening exponent, $\mathrm{n}$ & 0.26 & Damage constant, $\mathrm{D}_{5}$ & 0.61 \\
\hline Strain rate constant, $\mathrm{C}$ & 0.014 & Melting temperature, $(\mathrm{K})$ & $1.793 \mathrm{E}+3$ \\
\hline $\begin{array}{l}\text { Thermal softening exponent, } \\
\text { m }\end{array}$ & 1.03 & Ref. Strain rate, $\left(\mathrm{s}^{-1}\right)$ & 1 \\
\hline Melting temperature, $(\mathrm{K})$ & $1.793 \mathrm{E}+00$ & Erosion strain & 1.5 \\
\hline
\end{tabular}


to plastic flow as a function of the principal stresses $\sigma_{1}, \sigma_{2}$ and $\sigma_{3}$; the yield strength " $Y$ " is represented by [11]:

$$
\left(\sigma_{1}-\sigma_{2}\right)^{2}+\left(\sigma_{2}-\sigma_{3}\right)^{2}+\left(\sigma_{3}-\sigma_{1}\right)^{2}=2 Y^{2}
$$

For ceramic materials, "Johnson-Holmquist" (JH-2) Brittle Damage Model is used to represent brittle materials subjected to large pressures, shear strain and high strain rates. The material begins to soften when the damage begins to accumulate $(D>0)$. This allows for gradual softening of the material under increasing plastic strain. The strength and pressure are normalized by the strength and pressure components of the Hugoniot Elastic Limit (HEL), which allows for many of the constants to be dimensionless. This can be very helpful when comparing different materials. The equivalent stress, $\sigma^{*}$, for a ceramic-type material is given by [11]:

$$
\sigma^{*}=\sigma_{i}^{*}-D\left(\sigma_{i}^{*}-\sigma_{f}^{*}\right)
$$

The normalized intact strength, $\sigma_{i}{ }^{*}$, is given by [11]:

$$
\sigma_{i}^{*}=A\left(P^{*}+T^{*}\right)^{N}\left(1+C^{*} \ln \varepsilon^{\bullet *}\right),
$$

The normalized fracture strength, $\sigma_{f}{ }^{*}$, is given by [11]:

$$
\sigma_{f}^{*}=B\left(P^{*}\right)^{M}\left(1+C^{*} \ln \varepsilon^{\bullet *}\right),
$$

where

$$
\begin{gathered}
\sigma^{*}=\sigma / \sigma_{H E L}, \\
P^{*}=P / P_{H E L} \quad, \quad T^{*}=T / P_{H E L},
\end{gathered}
$$

and

$$
\varepsilon^{\bullet *}=\varepsilon^{\bullet} / \varepsilon_{o}^{\bullet},
$$

$\sigma_{H E L}$ is the stress at the (HEL), A, B, C, M, N are dimensionless material parameters, $\mathrm{P}$ is the actual pressure and $\mathrm{P}_{\mathrm{HEL}}$ is the pressure at the HEL, $\mathrm{T}$ is the maximum tensile hydrostatic pressure, $\varepsilon^{\bullet}$ is the actual equivalent strain rate and ${\varepsilon_{o}^{\bullet}}^{\bullet}$ is the reference strain rate. The damage parameter $D$ is defined as:

$$
D=\frac{\sum \Delta \varepsilon^{P}}{\varepsilon_{f}^{p}},
$$

where $\Delta \varepsilon^{p}$ is the incremental plastic strain per computational cycle, $\varepsilon_{f}^{p}$ is the plastic strain to fracture, which is calculated by:

$$
\varepsilon_{f}^{p}=D_{1}\left(P^{*}+T^{*}\right)^{D_{2}},
$$


where, $D_{1}$ and $D_{2}$ are additional damage material constants. Likewise, for each element, fracture occurs when $D=1$ [12]. The actual determination of ceramic parameters is complicated since it can not be determined directly and required different types of testing. Some of these constants, such as $B$ and $M$ which represent fractured strength constant and fractured strength exponent, respectively, may be determined by comparing the numerical simulation results with the corresponding experimental measurements [13] as an iterative process in which the values of $B$ and $M$ are varied until the numerical results are matched with experiments [1].

"Johnson Cook" equation has been used to represent the strength behavior of materials subjected to large strains, high strain rates and high temperatures. In this model, yield stress varies depending on strain, strain rate and temperature. Johnson Cook model that defines the yield stress $Y$ for a semi-infinte steel armor is [14]:

$$
Y=\left[A+B \varepsilon_{p}^{n}\right]\left[1+C \ln \varepsilon_{p}^{*}\right]\left[1-T_{H}^{m}\right]
$$

where, $\mathrm{A}, \mathrm{B}, \mathrm{C}, \mathrm{n}, \mathrm{m}$ are material constants, $\varepsilon_{p}$ is the effective plastic strain, $\varepsilon_{p}^{*}$ is the normalized effective plastic strain rate, and $\mathrm{T}_{\mathrm{H}}$ is the homologous temperature which is calculated by:

$$
T_{H}=\left(T-T_{\text {room }}\right) /\left(T_{\text {melt }}-T_{\text {room }}\right) \text {. }
$$

\section{Failure model}

Materials usually fail under extreme loading conditions, resulting in crushed or cracked material. So, failure models are used to simulate the various ways at which materials fail. For projectile material, "plastic strain" failure model has been used. This model can be specified with any plastic flow model. Bulk failure in a cell occurs when the effective plastic strain exceeds the specified limit value. When this happens, the stress deviators are set to zero and, in post-failure flow in that cell, the material cannot sustain any shear strength [14].

For ceramic material, the Johnson-Holmquist strength model and Johnson-Holmquist failure model must be used together. The tensile behavior of the model allows the principal tensile stress, failure initiation, and the hydrodynamic tensile limit to improve the representation of radial and cone cracks in impact simulations. For a semi-infinite metallic armor, "Johnson Cook" failure model has been used, which is constructed like "JohnsonCook" strength model as it defines the dynamic fracture strain as a function of pressure, strain rate and temperature as follows [14]:

$$
\begin{aligned}
& \varepsilon^{f}=\underbrace{\left[D_{1}+D_{2} e^{D_{3} \sigma^{*}}\right.} \underbrace{\left[1+D_{4} \ln \mid \varepsilon^{* *}\right.} \underbrace{[]\left[1+D_{5} T^{*}\right]} \\
& \text { Pressure Strain rate Temperature } \\
& \text { dependence dependence dependence }
\end{aligned}
$$

where $D_{1}$ up to $D_{5}$ are material damage constants. 


\section{Erosion Algorithm}

Incremental geometric strain has been selected for all parts (projectile, ceramic tile, and semi-

infinite armor). The strain value of projectile material and that of semi-infinite armor material have been taken as a constant with impact velocities and ceramic type $[10,15]$. For each ceramic type, the value is constant and varies from type to type. These values are the result of many trials to predict depth of penetration values close to their corresponding experimental values.

\section{Selecting the Solver, Defining Geometry and Zoning of Parts}

A Lagrangian solver has been selected for all parts, which is normally used for modelling solid continua in which the nodes move with the material. Lagrangian coordinate system will deform with the material and therefore accurately define material interfaces as shown in Fig. 2. The main dimensions of projectile and target (ceramic/semi-infinite) are converted into sub-grids with vertical and horizontal lines (grid lines), joining ceramic tile with metal back as shown in Fig. 3.

For the interaction between the projectile and target, Lagrange/Lagrange solver is used with external gap size which is calculated and checked automatically. The maximum gap size is half the smallest face dimension of all surface faces involved in interactions [16]. From zoning option in the program, a target point has been added in the rear end of the projectile to predict the velocity of projectile tail during the penetration process and plots it with time. The plotted $(\mathrm{V}-\mathrm{t})$ relation will stop either when the projectile is completely eroded or when the penetration velocity attains zero value.

\section{Time Step}

Since the numerical algorithm used in AUTODYN is an explicit scheme, there is an optimum time step of integration which must be determined to obtain a reasonably accurate solution. The local time step ensuring the stability is calculated for each mesh point. The minimum value of all these local values, multiplied by a factor (a default value of $2 / 3$ is built into the code), is chosen as the time step for the next update. In Lagrangian mesh, the time step must satisfy Courant condition [10]. So, the time step is represented by [16]:

$$
\Delta \mathrm{t}<\frac{\mathrm{d}}{\mathrm{c}}
$$

where " $\mathrm{d}$ " is the typical length of the cell (defined as the area of the cell divided by its longer diagonal) and " $\mathrm{C}$ " is the local sound speed. This ensures that a disturbance does not propagate across a zone in a single time step. The minimum value of " $\Delta \mathrm{t}$ " must be found for all cells and this value will be used for these cells for the next time step of integration.

\section{Program Running}

The expected number of cycles and estimated time of projectile penetration into each bielement target until it stops or is completely erdoded were fed into the program. In 
addition, the erosion strain and time step were selected. The program was run to predict the depth of penetration at each impact velocity, pressure contours, and time histories of projectile velocity, displacement ...etc.

\section{RESULTS AND DISCUSSIONS}

In the following, the results of the present numerical work are presented and classified into: (i)

validation of numerical results obtained by Autodyn-2D, and (ii) predictions. These predictions are concerened with the determination of ballistic efficiencies of different ceramic materials based on the predicted total projectile penetration depth into a semiinfinite steel armor and residual penetration depth into a semi-infinite steel armor when backing a ceramic tile. The influence of ceramic tile thickness on its ballistic efficiency is also presented. In addition, samples of the time histories of projectile velocity and its penetration depth into the bi-element targets are presented.

\section{Validation of Numerical Results Obtained by Autodyn-2D}

In the following, the numerical results obtained by Autodyn-2D hydrocode are validated by comparing them with the corresponding experimental measurements of Ref. [1]. For each ceramic type, Table 4 lists the measured total depth of penetration into bi-element target and the residual penetration depth into semi-infinite steel armor of Ref. [1] as well as their corresponding predicted values obtained by the hydrocode at each impact velocity. The absolute relative difference between the measured and predicted total penetration depth at each impact velocity, $\Delta Z\left(=\left[\left(Z_{\text {Exp }}-Z_{\text {Auto }}\right) / Z_{\text {Exp }}\right] \times 100\right)$, is also listed in the same table.

For each ceramic type, it is found that both the total penetration depth into a bi-element target and the residual penetration depth into a semi-infinite steel backing armor predicted by the hydrocode are in good agreement with the corresponding experimental measurements of Ref. [1] at each impact velocity. In addition, the maximum absolute relative difference between the measured total penetration depth of Ref. [1] and the corresponding predicted value obtained by the hydrocode is found to be $14.7 \%$ when a tungsten alloy projectile impacts an inclined bi-element target by $30^{\circ}$ at $V_{i}=1750 \mathrm{~m} / \mathrm{s}$.; the target consists of a $15 \mathrm{~mm}$-thick $\mathrm{SiC}$ ceramic tile backed by a semi-infinite steel armor.

Quan, et al. [7] used the Autodyn-3D hydrocode to simulate the penetration process of tungsten alloy projectiles into bi-element targets that were tested in Ref. [1] at different impact velocities. Each bi-element target consisted of a $\mathrm{SiC}$ ceramic tile backed by a semi-infinite 4340 steel armor. They used $(\mathrm{JH}-1)$ model to represent the strength model of $\mathrm{SiC}$ ceramic tile thickness in the hydrocode. It was found that the maximum absolute relative difference between their predicted total penetration depth by Autodyn-3D hydrocode and the corresponding experimental measurement of Ref. [1] was $28 \%$ when a tungsten alloy projectile impacted an inclined bi-element target by $45^{\circ}$ at $\mathrm{V}_{\mathrm{i}}=1710 \mathrm{~m} / \mathrm{s}$.; the target consisted of a $15.1 \mathrm{~mm}$-thick SiC ceramic tile backed by a semi-infinite steel armor.

The introduced numerical results reflect potential capabilities of Autodyn-2D hydrocode when it runs using the proper models simulating the strength, failure and erosion for the material of each constituent contributing to the penetration process. 
For each impact velocity, Figure 4 plots the predicted penetration depths obtained by Autodyn-2D hydrocode when each AD96 ceramic tile with a certain thickness faces a bielement target. The corresponding measured total penetration depth of Ref. [1] is plotted for each run number on the same figure. The maximum absolute relative difference between the measured and corresponding predicted total penetration depth is found to be $11.3 \%$ when a tungsten alloy projectile impacted an inclined bi-element target by $30^{\circ}$ at $V_{i}$ $=1740 \mathrm{~m} / \mathrm{s}$.; the target consisted of a $29.9 \mathrm{~mm}$-thick AD96 ceramic tile backed by a semiinfinite steel armor. Similarly, Figure5 plots the penetration depths obtained numerically by the hydrocode for bi-element targets faced by $\mathrm{B}_{4} \mathrm{C}$ ceramic tiles. The corresponding measured total penetration depths of Ref. [1] are plotted on the same figure. The maximum absolute relative difference between the measured and corresponding total penetration depth is found to be $13.4 \%$ when

Table 4. Experimental measurements of Ref. [1] and the corresponding numerical results of Autodyn-2D hydrocode due to the impact of tungsten alloy projectiles into bielement targets at different velocities.

\begin{tabular}{|c|c|c|c|c|c|c|c|c|c|}
\hline \multirow{2}{*}{$\begin{array}{c}\text { Ru } \\
\text { n } \\
\text { no. }\end{array}$} & \multirow{2}{*}{$\begin{array}{l}\text { Cera } \\
\text { mic } \\
\text { type }\end{array}$} & \multirow{2}{*}{$\begin{array}{c}\text { Cer. } \\
\text { Tile } \\
\text { thick., } \\
\mathbf{H}_{\mathrm{co}} \\
\text { [mm] }\end{array}$} & \multirow{2}{*}{$\begin{array}{c}\text { Impac } \\
t \\
\text { velocit } \\
y, v_{i} \\
{[\mathrm{~m} / \mathrm{s}]}\end{array}$} & \multirow{2}{*}{$\begin{array}{c}\text { Impa } \\
\text { ct } \\
\text { angle } \\
\left.{ }_{[0]}^{\circ}\right]\end{array}$} & \multicolumn{2}{|c|}{$\begin{array}{l}\text { Total depth of } \\
\text { penetration, } \mathrm{Z} \\
{[\mathrm{mm}]}\end{array}$} & \multicolumn{2}{|c|}{$\begin{array}{c}\text { Residual } \\
\text { penetration depth, } \\
Z_{\text {res }}[\mathrm{mm}]\end{array}$} & \multirow{2}{*}{$\begin{array}{c}\text { Abs. } \\
\text { Relative } \\
\text { differ. in } \\
\text { total } \\
\text { penetratio } \\
n, \\
\Delta Z[\%]\end{array}$} \\
\hline & & & & & $Z_{\text {Exp }}[1]$ & $Z_{\text {Auto }}$ & $\begin{array}{c}\text { Exper. } \\
\text { [1] }\end{array}$ & $\begin{array}{c}\text { Autody } \\
\text { n }\end{array}$ & \\
\hline 1 & \multirow{7}{*}{ AD85 } & 6.2 & 1330 & \multirow{7}{*}{0.0} & 24.7 & 24.55 & 18.5 & 18.36 & 0.6 \\
\hline 2 & & 14.5 & 1350 & & 25.8 & 27.72 & 11.3 & 13.22 & 7 \\
\hline 3 & & 22.1 & 1350 & & 29.6 & 29.6 & 7.5 & 7.5 & 0 \\
\hline 4 & & 32 & 1370 & & 35.8 & 33.22 & 3.8 & 1.22 & 7.2 \\
\hline 5 & & 14 & 1750 & & 36 & 32.5 & 22 & 18.5 & 9.7 \\
\hline 6 & & 29.9 & 1750 & & 39.9 & 37 & 10 & 7.1 & 7.3 \\
\hline 7 & & 42.5 & 1770 & & 45.2 & 42.5 & 2.7 & 0.0 & 6 \\
\hline 8 & \multirow{15}{*}{ AD96 } & 10.5 & 1350 & \multirow{8}{*}{0.0} & 25 & 25.9 & 14.5 & 15.4 & 3.6 \\
\hline 9 & & 15.1 & 1350 & & 26.2 & 26.9 & 11.1 & 11.8 & 2.7 \\
\hline 10 & & 20.6 & 1360 & & 29.3 & 29.4 & 8.7 & 8.84 & 0.5 \\
\hline 11 & & 30.2 & 1360 & & 34.2 & 31.2 & 4 & 1 & 8.8 \\
\hline 12 & & 20.4 & 1680 & & 36.2 & 32.5 & 15.8 & 12.1 & 10.2 \\
\hline 13 & & 31.7 & 1720 & & 38.1 & 35.2 & 6.4 & 3.5 & 7.6 \\
\hline 14 & & 40 & 1700 & & $--^{*}$ & 40 & 0 & 0 & $--^{*}$ \\
\hline 15 & & 40.4 & 1800 & & 40.9 & 40.4 & 0.5 & 0 & 1.2 \\
\hline 16 & & 15.1 & 1690 & 30 & 29.1 & 30.1 & 14 & 14.98 & 3.4 \\
\hline 17 & & 29.9 & 1740 & 30 & 35.4 & 31.4 & 5.5 & 1.5 & 11.3 \\
\hline 18 & & 15.3 & 1800 & 45 & 24.8 & 25.2 & 9.5 & 9.89 & 1.6 \\
\hline 19 & & 25 & 1720 & 45 & $-^{-*}$ & 25 & 0 & 0 & $--^{*}$ \\
\hline 20 & & 10.5 & 1740 & 60 & 17.2 & 16.3 & 6.7 & 5.75 & 5.5 \\
\hline 21 & & 15.2 & 1740 & 60 & 19.3 & 18.2 & 4.1 & 3 & 5.7 \\
\hline 22 & & 20 & 1740 & 60 & $--^{*}$ & 20 & 0 & 0 & $--^{*}$ \\
\hline 23 & \multirow{3}{*}{$\mathrm{B}_{4} \mathrm{C}$} & 19.3 & 1740 & 0 & 39.1 & 35.76 & 19.8 & 16.46 & 8.5 \\
\hline 24 & & 28.8 & 1780 & 0 & 38.6 & 38.3 & 9.8 & 9.5 & 0.8 \\
\hline 25 & & 28 & 1790 & 30 & 31.3 & 35.5 & 3.3 & 7.5 & 13.4 \\
\hline
\end{tabular}




\begin{tabular}{|c|c|c|c|c|c|c|c|c|c|}
\hline 26 & & 17.6 & 1770 & 60 & 19.8 & 21.17 & 2.2 & 3.57 & 6.9 \\
\hline 27 & & 10.4 & 1280 & 0 & 23.7 & 25.76 & 13.3 & 15.36 & 8.7 \\
\hline 28 & \multirow{15}{*}{$\mathrm{SiC}$} & 30.1 & 1310 & \multirow{8}{*}{0} & $-^{*}$ & 32.5 & 0 & 2.4 & $--^{*}$ \\
\hline 29 & & 10 & 1370 & & 23.9 & 24.02 & 13.9 & 14.02 & 0.5 \\
\hline 30 & & 15.1 & 1360 & & 27.1 & 25.5 & 12 & 10.5 & 5.5 \\
\hline 31 & & 20 & 1690 & & 34.3 & 30.65 & 14.3 & 10.65 & 10.6 \\
\hline 32 & & 20 & 1750 & & 34.5 & 30.8 & 14.5 & 10.8 & 10.7 \\
\hline 33 & & 29.5 & 1770 & & 32.2 & 32.5 & 2.7 & 3 & 7.7 \\
\hline 34 & & 30.2 & 1700 & & 32.6 & 33 & 2.4 & 2.8 & 1.2 \\
\hline 35 & & 40 & 1740 & & $-^{*}$ & 40 & 0 & 0 & $--^{*}$ \\
\hline 36 & & 15 & 1750 & \multirow{2}{*}{30} & 29.9 & 25.5 & 14.9 & 10.5 & 14.7 \\
\hline 37 & & 31.3 & 1780 & & 32.3 & 31.3 & 1 & 0 & 3.1 \\
\hline 38 & & 15.1 & 1710 & \multirow{2}{*}{45} & 23.3 & 22.1 & 8.2 & 7 & 5.2 \\
\hline 39 & & 25 & 1810 & & $-^{*}$ & 25.55 & 0 & 0.55 & $--^{*}$ \\
\hline 40 & & 10.1 & 1700 & \multirow{3}{*}{60} & 16.7 & 15.6 & 6.6 & 5.5 & 6.6 \\
\hline 41 & & 14.9 & 1800 & & 16.8 & 16.3 & 1.9 & 1.4 & 3 \\
\hline 42 & & 20 & 1690 & & $-^{*}$ & 20 & 0 & 0 & $--^{\star}$ \\
\hline 43 & \multirow{8}{*}{ AIN } & 9.7 & 1250 & \multirow{6}{*}{0.0} & 19.8 & 22.2 & 10.1 & 12.5 & 12.1 \\
\hline 44 & & 14.3 & 1300 & & 23.2 & 24.75 & 8.9 & 10.45 & 6.7 \\
\hline 45 & & 19.6 & 1310 & & 23.9 & 22.2 & 4.3 & 2.6 & 7.1 \\
\hline 46 & & 19.7 & 1790 & & 34 & 31.03 & 14.3 & 11.33 & 8.7 \\
\hline 47 & & 28.8 & 1800 & & 37.3 & 34.99 & 8.5 & 6.19 & 6.2 \\
\hline 48 & & 37 & 1790 & & $--^{*}$ & 37 & 0 & 0 & $--^{*}$ \\
\hline 49 & & 28.2 & 1760 & 30 & 29.8 & 29.2 & 1.6 & 1 & 2 \\
\hline 50 & & 27.5 & 1780 & 60 & $-^{*}$ & 27.5 & 0 & 0 & $--^{*}$ \\
\hline
\end{tabular}

Table 4. Experimental measurements of Ref. [1] and the corresponding numerical results of Autodyn-2D hydrocode due to the impact of tungsten alloy projectiles into bielement targets at different velocities (Contd.).

\begin{tabular}{|c|c|c|c|c|c|c|c|c|c|}
\hline \multirow{2}{*}{$\begin{array}{c}\text { Ru } \\
\text { n } \\
\text { no. }\end{array}$} & \multirow{2}{*}{$\begin{array}{l}\text { Cera } \\
\text { mic } \\
\text { type }\end{array}$} & \multirow{2}{*}{$\begin{array}{c}\text { Cer. } \\
\text { Tile } \\
\text { thick., } \\
H_{\text {co }} \\
{[\mathrm{mm}]}\end{array}$} & \multirow{2}{*}{$\begin{array}{c}\text { Impac } \\
t \\
\text { velocit } \\
y, v_{i} \\
{[\mathrm{~m} / \mathrm{s}]}\end{array}$} & \multirow{2}{*}{$\begin{array}{c}\text { Impa } \\
\text { ct } \\
\text { angle } \\
{ }_{\left[{ }^{\circ}\right]}\end{array}$} & \multicolumn{2}{|c|}{$\begin{array}{l}\text { Total depth of } \\
\text { penetration, } \mathrm{Z} \\
\text { [mm] }\end{array}$} & \multicolumn{2}{|c|}{$\begin{array}{c}\text { Residual } \\
\text { penetration depth, } \\
Z_{\text {res }}[\mathrm{mm}]\end{array}$} & \multirow{2}{*}{$\begin{array}{c}\text { Abs. } \\
\text { Relative } \\
\text { differ. in } \\
\text { total } \\
\text { penetratio } \\
\text { n, } \\
\Delta \mathbf{Z}[\%]\end{array}$} \\
\hline & & & & & $Z_{\operatorname{Exp}}[1]$ & $Z_{\text {Auto }}$ & $\begin{array}{c}\text { Exper. } \\
\text { [1] }\end{array}$ & $\begin{array}{l}\text { Autody } \\
\text { n }\end{array}$ & \\
\hline 51 & \multirow{9}{*}{$\mathrm{TiB}_{2}$} & 20 & 1370 & \multirow{4}{*}{0.0} & $--^{*}$ & 20 & 0 & 0 & 0 \\
\hline 52 & & 10.1 & 1690 & & 22.2 & 25 & 12.1 & 14.9 & 12.6 \\
\hline 53 & & 14.9 & 1700 & & 22.2 & 23.53 & 7.3 & 8.63 & 6 \\
\hline 54 & & 30 & 1690 & & $-^{*}$ & 30 & 0 & 0 & $--^{*}$ \\
\hline 55 & & 10.1 & 1700 & \multirow{2}{*}{30} & 19.5 & 20.59 & 9.4 & 10.49 & 5.6 \\
\hline 56 & & 25 & 1800 & & $--^{*}$ & 25 & 0 & 0 & $--^{*}$ \\
\hline 57 & & 20 & 1690 & 45 & $--^{*}$ & 20 & 0 & 0 & $--^{*}$ \\
\hline 58 & & 7.8 & 1800 & \multirow{2}{*}{60} & 13.4 & 12.1 & 5.6 & 4.3 & 9.7 \\
\hline 59 & & 15 & 1810 & & $--^{*}$ & 0 & 0 & 0 & $--^{*}$ \\
\hline
\end{tabular}

* Measured penetration depth into respective ceramic tile is not mentioned in Ref. [1]. 
a tungsten alloy projectile impacts an inclined bi-element target by $30^{\circ}$ at $V_{i}=1790 \mathrm{~m} / \mathrm{s}$.; the target consists of a $28 \mathrm{~mm}$-thick of $\mathrm{B}_{4} \mathrm{C}$ ceramic tile backed by a semi-infinite steel armor.

\section{Predictions}

\section{Ballistic efficiencies of ceramic materials}

For each ceramic type, the ballistic efficiency, $E_{m}$, of each ceramic tile thickness is calculated using the following equation [17]:

$$
E_{m}=\rho_{S t}\left(Z_{S t}-Z_{\text {res }}\right) / \rho_{c} H_{c o}
$$

where $\rho_{S t}$ is the density of semi-infinite steel armor material, $Z_{S t}$ is the total penetration depth of a projectile into a semi-infinite steel armor alone, $Z_{\text {res }}$ is the residual penetration depth into a semi-infinite steel armor when it backs a ceramic tile with a certain thickness, $\rho_{c}$ is the density of ceramic tile material and $\mathrm{H}_{\mathrm{co}}$ is the initial thickness of ceramic tile.

Figure 6 shows the predicted change of ballistic efficiency for different thicknesses of AD96 ceramic with impact velocity. For each thickness, the ballistic efficiency of AD96 ceramic tile increases with impact velocity. In addition, the ceramic tile with highest thickness could not withstand the projectile penetration, which resulted in more penetration depth into 4340 semi-infinite steel backing armor over the considered impact velocity range. Therefore, the ballistic efficiency of $5 \mathrm{~mm}$-thick AD96 ceramic is greater than that of the other thicknesses over the impact velocity range of $1350-1700 \mathrm{~m} / \mathrm{s}$. So, it is recommended to use the lowest tile thickness of AD96 ceramic type to face the semiinfinite steel armor at this particular range of impact velocity. The obtained numerical results of Autodyn-2D are in good agreement with those predicted by the analytical model of Ref. [17].

Figure 7 plots the predicted change of ballistic efficiency of $20 \mathrm{~mm}$-thick AD96, $\mathrm{TiB}_{2}$, and $\mathrm{B}_{4} \mathrm{C}$ ceramic types, respectively, with impact velocity. It is seen from the figure that the ballistic efficiency for each ceramic type increases with impact velocity and the ballistic efficiency of $\mathrm{B}_{4} \mathrm{C}$ ceramic tile is always greater than that of the other two types of ceramics over the impact velocity range of 1350 to $1700 \mathrm{~m} / \mathrm{s}$. However, $\mathrm{TiB}_{2}$ ceramic type has a high density compared to AD96 ceramic type, the ballistic efficiency of $\mathrm{TiB}_{2}$ ceramic is always greater than that of AD96 ceramic; this may be attributed to the high $\mathrm{HEL}$ of $\mathrm{TiB}_{2}$ ceramic which resists the projectile penetration and results in low residual penetration into semi-infinite steel backing armor, Cf. Eqn. (16).

Figure 8 shows the predicted change of ballistic efficiency of SiC ceramic with different tile thicknesses at different impact velocities. It is seen from the figure that the ballistic efficiency always decreases with increasing ceramic thickness; this may be due to the decrease of the ratio $\left(Z_{s t}-Z_{\text {res }}\right) / H_{c o}$, cf. Eqn. (16). Figure 9 also shows the predicted change of ballistic efficiency with ceramic thickness for different types of ceramics at the impact velocity of $1450 \mathrm{~m} / \mathrm{s}$. For each type of ceramic, the ballistic efficiency decreases with increasing tile thickness. It is also seen from the figure that the ballistic efficiency of $\mathrm{B}_{4} \mathrm{C}$ ceramic is always greater than that of the other ceramic types. The other ceramic types are ordered descendingly according to their ballistic efficiencies as $\mathrm{SiC}, \mathrm{TiB}_{2}$, then AD96. 
Figure 10 plots the predicted change of residual penetration depth into semi-infinite steel armor backing AD96 ceramic tiles with different thicknesses at different impact velocities. It is seen from the figure that the residual penetration depth decreases with increasing ceramic tile thickness at each impact velocity. In addition, the slope " $\mathbf{Z}_{\text {res }} / \mathbf{H}_{\text {co }}$ " is approximately constant for each impact velocity considered. This means that the ratio of " $\mathrm{Z}_{\text {res }} / \mathrm{H}_{\mathrm{co}}$ " is independent of impact velocity and ceramic thickness. This result is similar to that obtained by Rosenberg, et al. [2] and Huang and Zhang [18] for the alumina class of ceramic.

Figure 11 plots the predicted change of residual penetration depths into semi-infinite steel armor which backs each tile thickness of different ceramic types at the impact velocity of $1450 \mathrm{~m} / \mathrm{s}$. For each ceramic type, the figure shows that the residual penetration decreases with the increase of ceramic thickness. Also, $\mathrm{TiB}_{2}$ ceramic type resumes the lowest residual penetration as it has the highest physical and mechanical properties compared to the other types of ceramic.

\section{Time histories results}

Figure 12 shows the penetration depth-time history of a tungsten alloy projectile into a 10.4

mm-thick $B_{4} C$ ceramic tile backed by a semi-infinite steel armor at $V_{i}=1280 \mathrm{~m} / \mathrm{s}$. It is clear from the figure that both the projectile and ceramic tile are subjected to erosion during the early stage of penetration. In addition, the projectile completes its erosion during its penetration into the backing steel armor until it finally vanishes. The Autodyn-2D hydrocode predicts that the residual penetration of projectile into the semi-inifnite steel armor when it completely erodes is $15.36 \mathrm{~mm}$. The corresponding measured residual penetration obtained by Ref. [1] is $13.3 \mathrm{~mm}$. The obtained results prove the potential predictive capabilities of the hydrocode as a useful tool for predicting the performance of a projectile during its penetration into a bi-element target.

Figure 13 also plots the velocity-time history of moving masses from projectile and bielement target described. The figure shows the continuous decrease in velocity of projectile rigid mass due to the deceleration exerted by the target. The present figure also shows that, both the semi-infinite armor and the remaining ceramic tile (unloaded zone) are stationary and only the remaining rod penetrates the semi-infinite armor; these observations support the assumptions considered by woodward [19] when developing his analytical model.

\section{CONCLUSIONS}

The main conclusions of the present work are:

- The numerical results obtained by Autodyn-2D for simulating the penetration process of a high-speed tungsten projectile into bi-element targets are in good agreement with the corresponding experimental measurements of Ref. [1].

- The numerical results obtained by Autodyn-2D draw the following:

- Residual penetration increases with the increase of impact velocity and decreases with the increase of ceramic tile thickness and its HEL.

- For alumina ceramic types the slope of $Z_{\text {res }} / H_{c o}$ is independed of impact velocity and ceramic tile thickness; this result is similar to that drawn from the experimental program of Rosenberg, et al. [2]. 
- The ballistic efficiencies of different ceramic types increase with their HEL and impact velocity except $\mathrm{B}_{4} \mathrm{C}$ ceramic type; this may be due to the density of the latter ceramic type which is low in comparison with the other types of ceramics.

- The obtained numerical results reflect potential predictive capabilities of Autodyn-2D hydrocode when it runs using the proper models simulating the strength, failure and erosion for the material of each constituent contributing to the penetration process.

\section{REFERENCES}

[1] J.E. Reaugh, A.C. Holt, M.L. Wilkins, B.J. Cunningham, B.L. Hord and A.S. Kusubov, "Impact Studies of Six Ceramic Materials and Pyrex", Int. J. Impact Eng., Vol. 23, pp. 77l-782 (1999).

[2] Z. Rosenberg, E. Dekel, V. Hohler, A.J. Stilp and K. Weber, "Hypervelocity Penetration of Tungsten Alloy Rods into Ceramic Tiles: Experiments and 2-D Simulations", Int. J. Impact Eng., Vol. 20, pp. 675-683 (1997).

[3] V. Hohler, A.J. Stilp and K. Weber, "Hypervelocity Penetration of Tungsten SinterAlloy Rods into Alumina", Int. J. Impact Eng., Vol. 17, pp. 409-418 (1995).

[4] T.J. Holmquist, D.W. Templeton and K.D. Bishnoi, "Constitutive Modelling of Aluminum Nitride for Large Strain, High-Strain Rate, and High-Pressure Applications", Int. J. Impact Eng., Vol. 25, pp. 211-231 (2001).

[5] K. Weber, T.J. Holmquist, and D.W. Templeton, "The Response of Layered Aluminum Nitride Targets Subjected to Hypervelocity Impact", Int. J. Impact Eng., Vol. 26, pp. 831-841 (2001).

[6] T.J. Holmquist and G.R. Johnson, "Modelling Prestressed Ceramic and Its Effect on Ballistic Performance", Int. J. Impact Eng., Vol. 31, pp. 113-127 (2005).

[7] X. Quan, R.A. Clegg, M.S. Cowler, N.K. Birnbaum and C.J. Hayhurst, "Numerical Simulation of Long Rods Impacting Silicon Carbide Targets Using JH-1 Model", Int. J. Impact Eng., Vol. 33, pp. 634-644 (2006).

[8] L. Westerling, P. Lundberg and B. Lundberg, " Tungsten Long-Rod Penetration into Confined Cylinders of Boron Carbide at and Above Ordnance Velocities", Int. J. Impact Eng., Vol. 25, pp. 703-714 (2001).

[9] N.K. Birnbaum, M. Cowler and C. Hayhurst, "Numerical Simulation of Impact Using Autodyn", Proc. $2^{\text {nd }}$ Int. Impact Sympo., Beijing, China (1996).

[10] "AUTODYN Users Manual", Revision 4.3 (2005).

[11] "Theory Manual of AUTODYN", Revision 4.3 (2005).

[12] Y.F. Wang and Z.G Yang, "Finite Element Model of Erosive Wear on Ductile and Brittle Materials", Int. J. Wear, Vol. 265, pp. 871-878 (2008).

[13] D.S. Cronin, K. Bui, C. Kaufmann, G. Mclntosh and T. Brestad, "Implementation and

Validation of the Johnson-Homlquist Ceramic Material Model in LS-DYNA", $4^{\text {th }}$ European LS-DYNA Users Conference (2003).

[14] "Material Models, AUTODYN Help", Version 6. (2006).

[15] C. Kaufmann and K. Williams, "Optimization of a Numerical Simulation Involving the Impact of an AP-T C44 12.7mm Projectile on a Semi-Infinite Monolithic 6061T6 Aluminum Target", Technical Memorandum, TM 2002-015, May (2004).

[16] "AUTODYN Training Course", Version 6.0 (2006).

[17] H.A. Abou-Elela and A.M. Riad,"Modeling Penetration of a high-Speed Projectile into Ceramic/Metal Targets", $13^{\text {th }}$ Int. Conf. on Aerospace Sci. and Aviation Tech. (ASAT-13), Military Technical College, Cairo, Egypt, 26-28 May (2009). 
[18] F.L. Huang and L.S. Zhang, "Investigation on Ballistic Performance of Armor Ceramics Against Long-Rod Penetration", Int. J. Metallurgical and Materials, Trans. A, Vol. 38A, pp. $2891-2895$ (2007).

[19] R.L. Woodward, "A Simple One-Dimensional Approach to Modelling Ceramic Composite Armor Defeat", Int. J. Impact Eng., Vol. 9, No. 4, pp. 455-474 (1990).

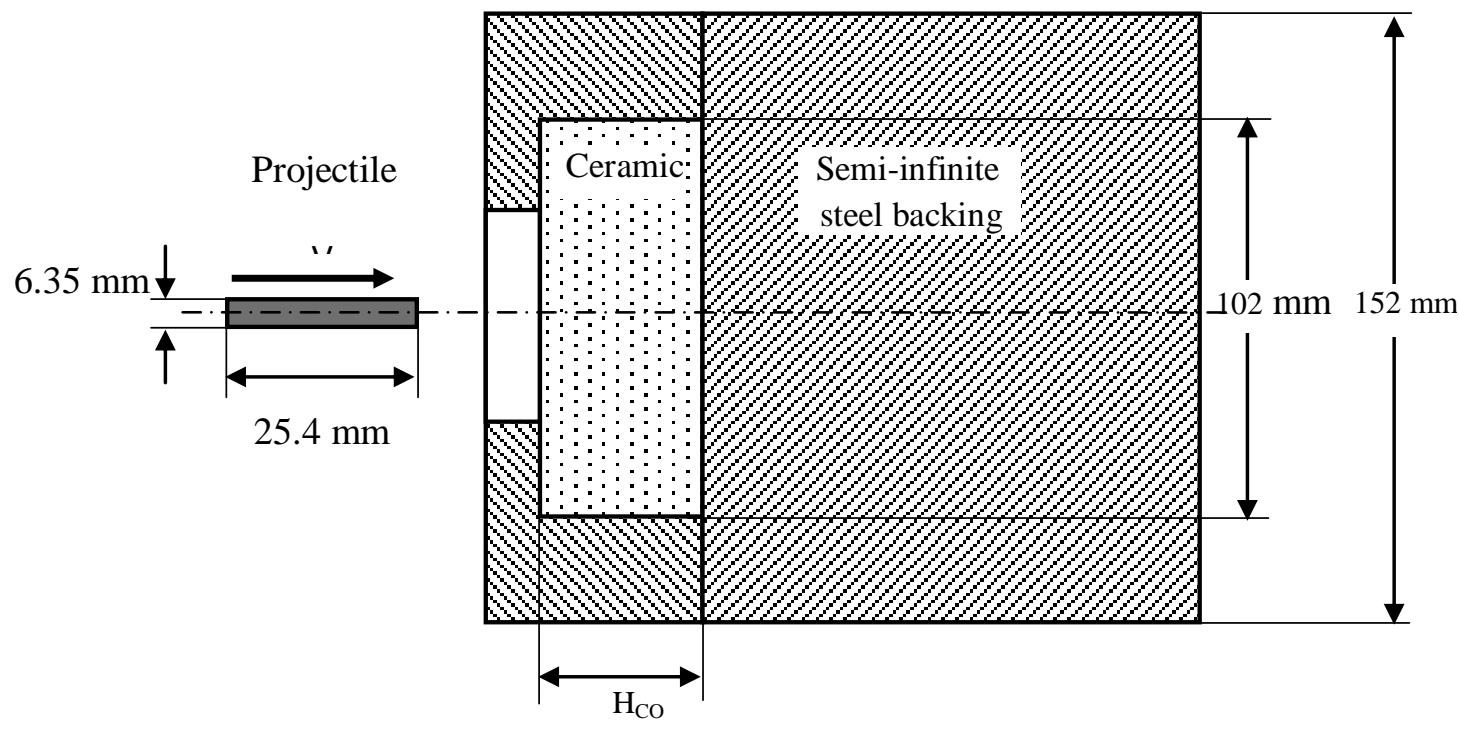

Fig. 1. A Schematic drawing of a tungsten projectile impact into a bi-element target.

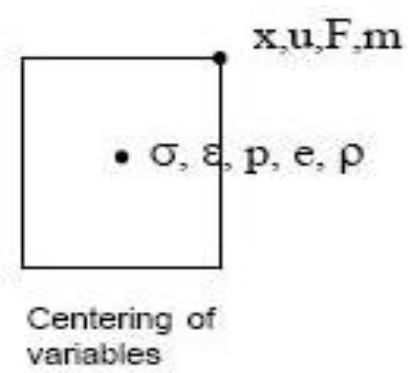

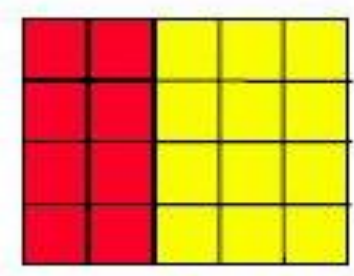

$\mathrm{t}=0.0$

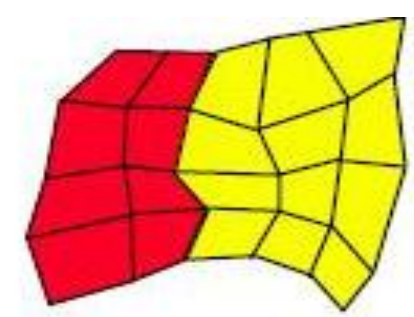

$\mathrm{t}=\mathrm{t}_{1}$

Fig. 2. Simulation of Lagrangian solver [11]. 


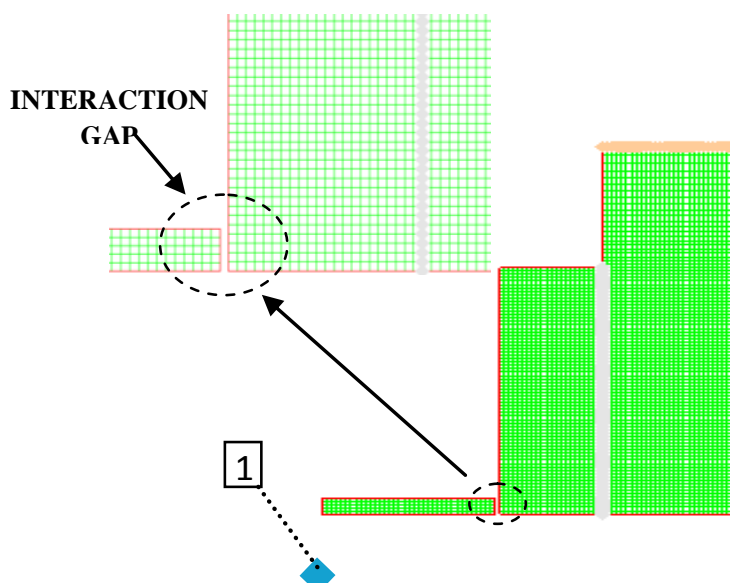

(a)

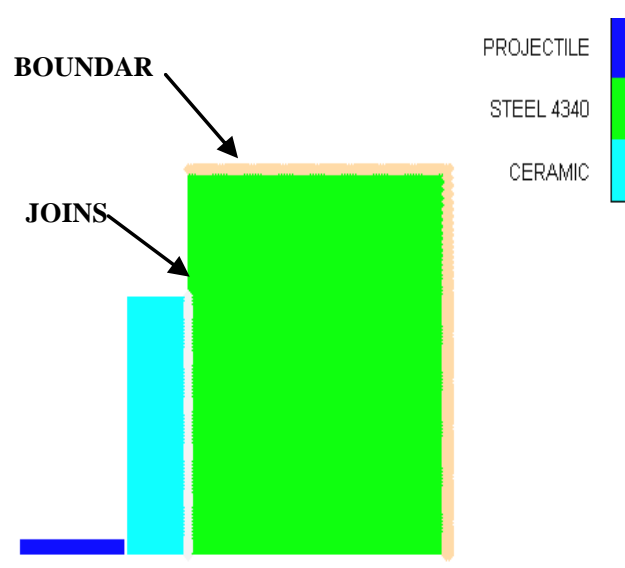

(b)

Fig. 3. Simulation of penetration of high speed projectile into ceramic/semi-infinite steel target. (a) grids of the parts, interaction gap and the target point No (1) and (b) materials locations, joins and boundary.

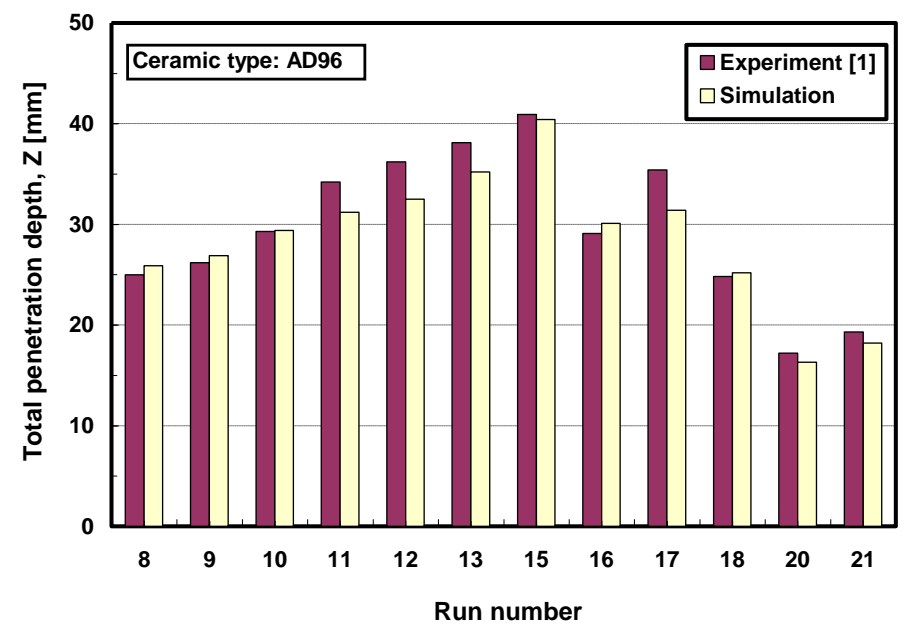

Fig. 4. Comparison between the measured penetration depths obtained by Ref. [1] and the corresponding numerical values obtained by Autodyn-2D at each run number when AD96 ceramic tiles face the bi-element targets. 


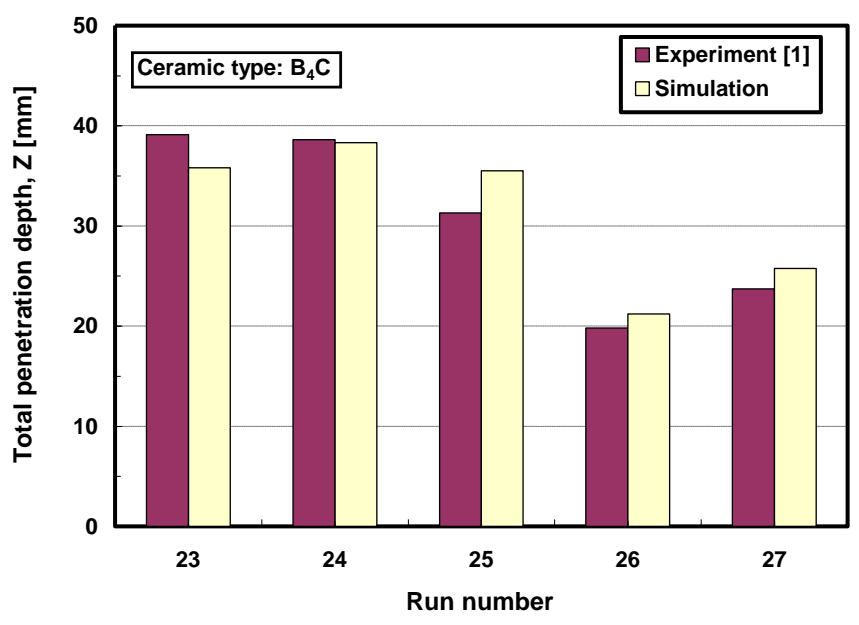

Fig. 5. Comparison between the measured penetration depths obtained by Ref. [1] and the corresponding numerical values obtained by Autodyn-2D at each run number when $\mathrm{B}_{4} \mathrm{C}$ ceramic tiles face the bi-element targets.

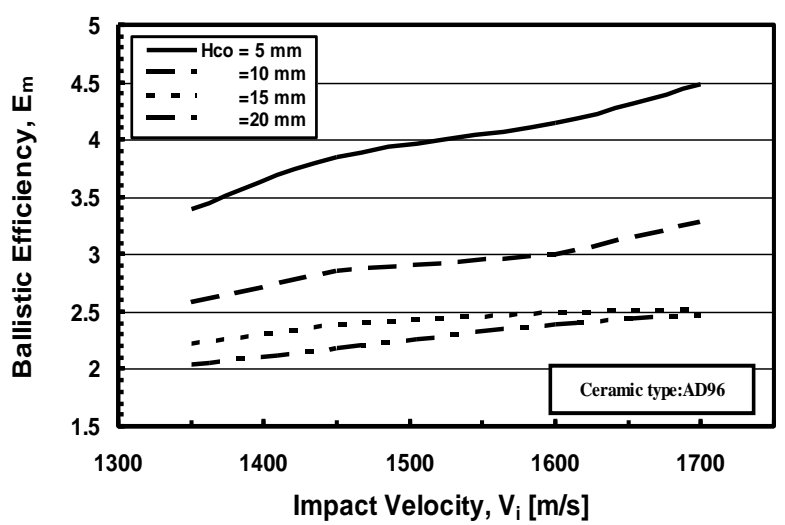

Fig. 6. Predicted change of ballistic efficiency with impact velocity for different AD96 ceramic tile thicknesses.

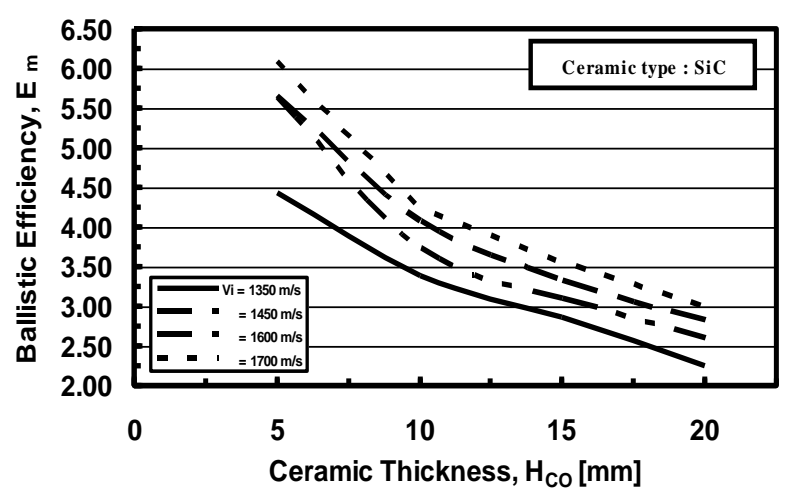

Fig. 8. Predicted change of ballistic efficiency of $\mathrm{SiC}$ ceramic tile with thickness at different impact velocities.

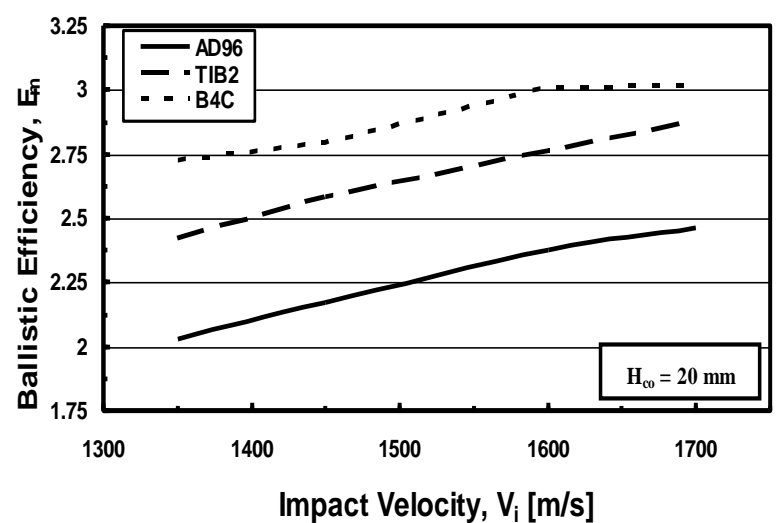

Fig. 7. Predicted change of ballistic efficiency with impact velocity for $20 \mathrm{~mm}$ AD96, $\mathrm{TiB}_{2}$ and $\mathrm{B}_{4} \mathrm{C}$ ceramic types.

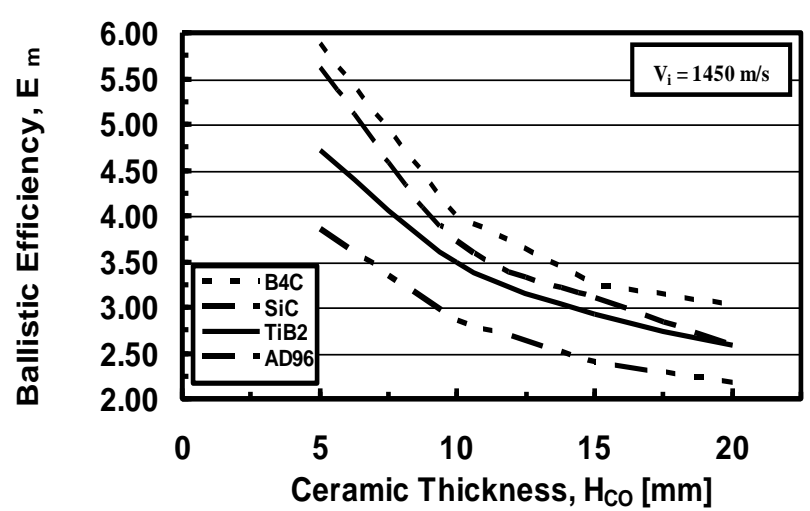

Fig. 9. Predicted change of ballistic efficiency with ceramic thickness for different ceramic types at $V_{i}=1450 \mathrm{~m} / \mathrm{s}$. 


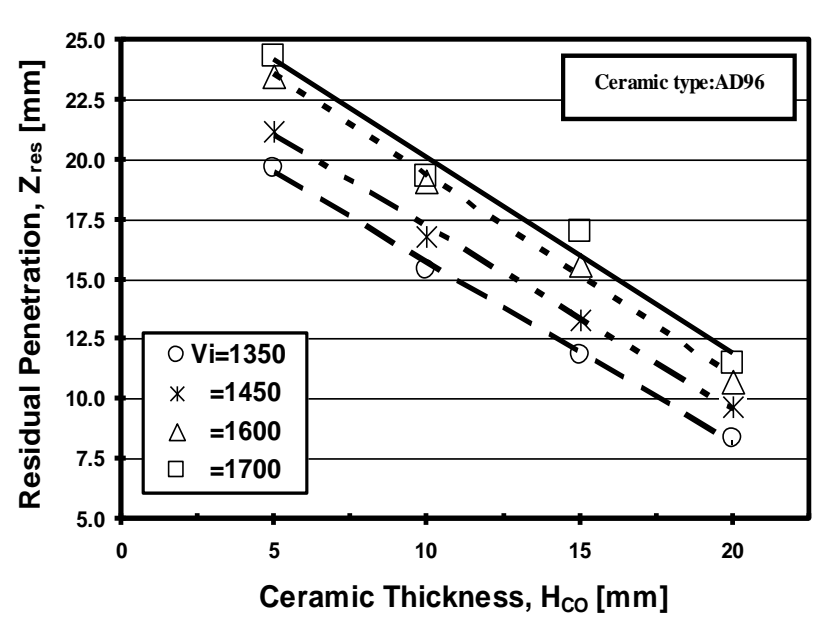

Fig. 10. Predicted change in residual penetration for different thicknesses of AD96 ceramic tiles at different impact velocities.

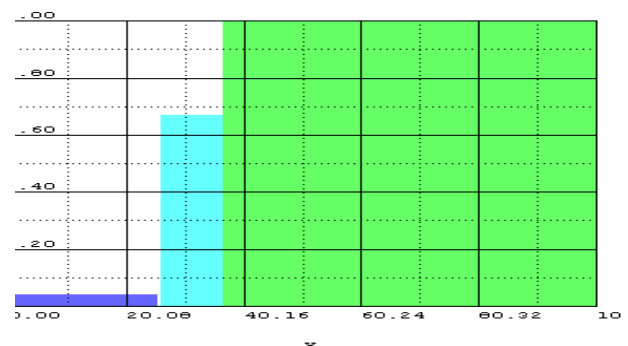

$$
\mathrm{t}=0 \mu \mathrm{s}
$$

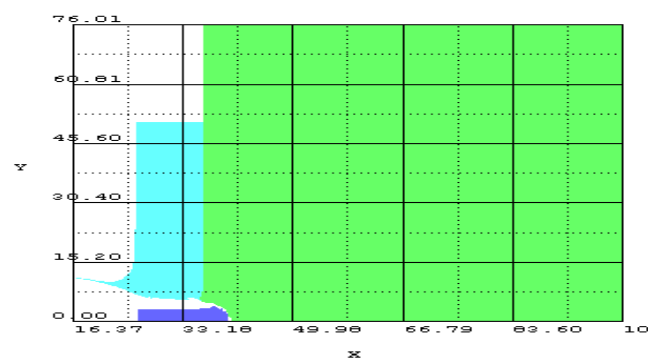

$\mathrm{t}=24.8 \mu \mathrm{s}$

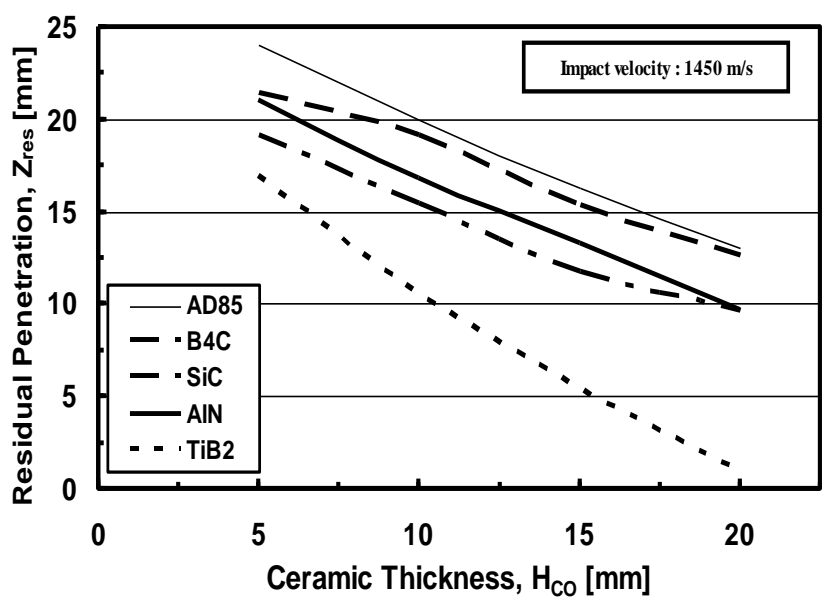

Fig. 11. Predicted change in residual penetration for different thicknesses of ceramic types at $V_{i}=1450 \mathrm{~m} / \mathrm{s}$.
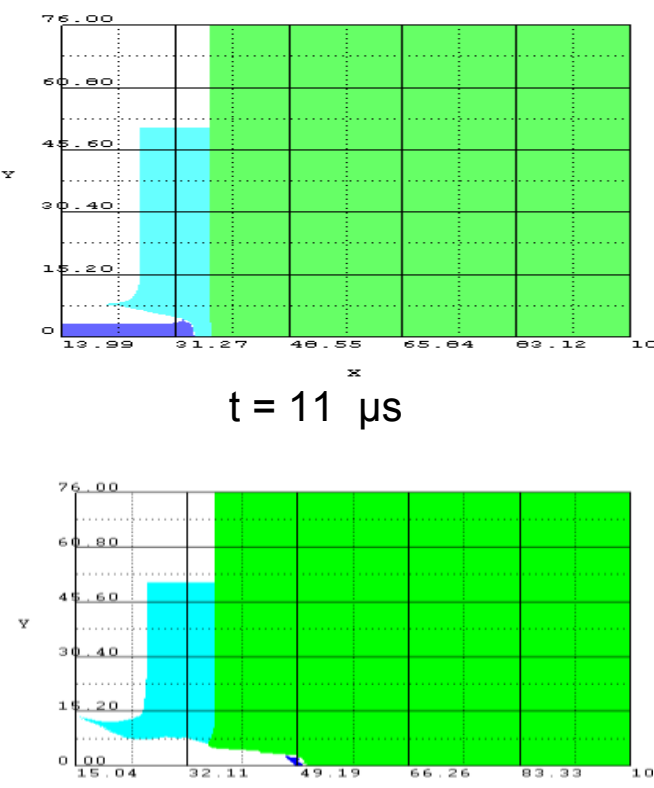

$$
\mathrm{t}=46.7 \mu \mathrm{xs}
$$

Fig. 12. Time history of projectile penetration depth into a bi-element target consisting of a $10.4 \mathrm{~mm}$-thick B4C ceramic tile backed by a semi-infinite 4340 steel armor at $V_{i}=1280$ $\mathrm{m} / \mathrm{s}$. 

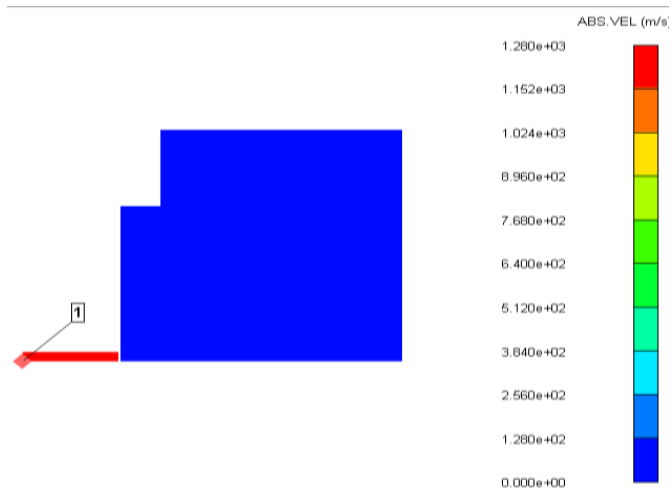

$$
t=0 \mu s
$$

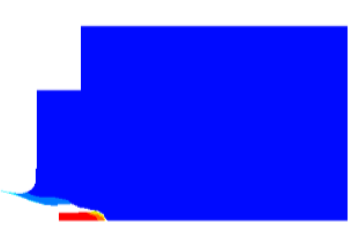

$$
\mathrm{t}=24.8 \mu \mathrm{s}
$$

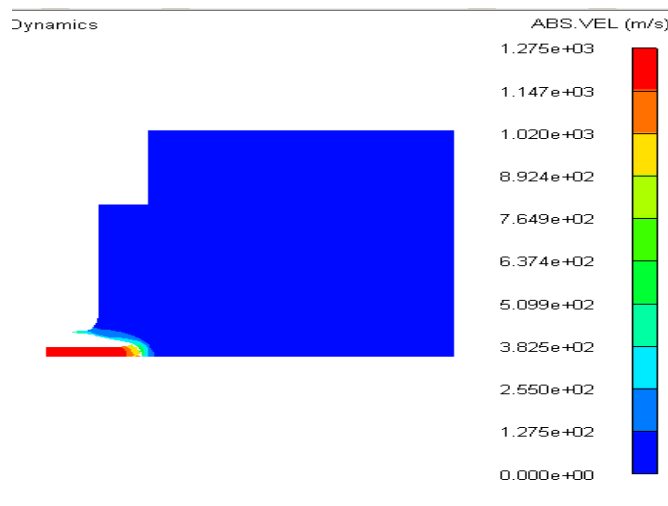

$$
t=11 \mu s t
$$

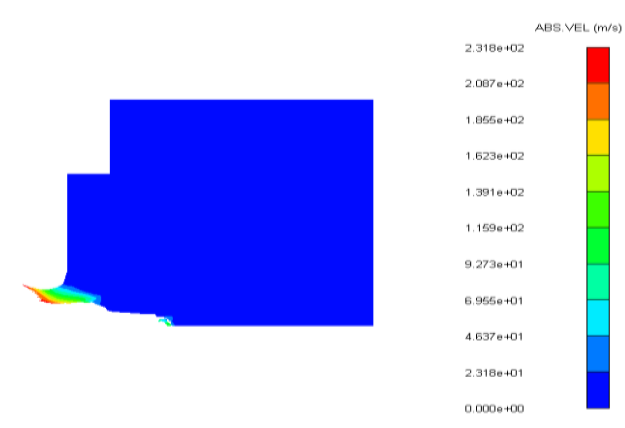

$$
\mathrm{t}=46.7 \mu \mathrm{s}
$$

Fig. 13. Velocity-time history when a projectile penetrates a bi-element armor consisting of $10.4 \mathrm{~mm}$-thick B4C ceramic tile backed by a semi-infinite 4340 steel armor at $\mathrm{V}_{\mathrm{i}}=1280 \mathrm{~m} / \mathrm{s}$. 


\section{NOMENCLATURE}

\section{Symbols}

$\begin{array}{cl}\mathrm{H}_{\mathrm{Co}} & \text { Initial thickness of ceramic tile. } \\ t & \text { Time of penetration. } \\ V & \text { Velocity of rigid mass of projectile at time t. } \\ V_{i} & \text { Impact velocity. } \\ Z & \text { Projectile penetration depth at time t. } \\ Z_{\mathrm{ex}} & \text { Measured total penetration depth of projectile into a bi-element } \\ Z_{\text {res }} & \text { target. } \\ \boldsymbol{O}^{\circ} & \text { Residual penetration depth into semi-infinite steel backing armor. } \\ & \text { Impact angle measured from the normal to the armor surface. }\end{array}$

\section{Abbreviations}

AD85 Alumina ceramic material with purity $85 \%$.

AD96 Alumina ceramic material with purity $96 \%$.

AIN Aluminum Nitride.

AP Armor Piercing projectile.

BHN Brinell Hardness Number.

$\mathrm{B}_{4} \mathrm{C} \quad$ Boron Carbide ceramic material.

DOP Depth of Penetration.

JH-1 Instantaneous Johnson Holmquist model.

$\mathrm{JH}-2$ Incremental Johnson Holmquist model.

HEL Hogonoit Elastic Limit.

RHA Rolled Homogeneous Armor.

$\mathrm{SiC} \quad$ Silicon Carbide ceramic material.

$\mathrm{TiB}_{2} \quad$ Titanium Diboride ceramic material. 